\title{
CASING EFFECTS ON THE RADIATION PERFORMANCE OF A CIRCULARLY POLARIZED PATCH ANTENNA
}

\author{
K. Rambabu, H.A. Thiart and J. Bornemann \\ Department of Electrical and Computer Engineering \\ University of Victoria, Victoria, B.C., Canada V8W 3P6
}

\section{INTRODUCTION}

Miniaturization is one of the prime motives in modern communication systems and can be achieved through size reduction of both components and their packages. Whereas passive components are fairly insensitive to packaging, this is certainly not the case for antennas as the package is located in the nearfield. Different packaging materials are used and usually vary with application [1]; e.g., high-power components require metal casing to meet EMI/EMC specifications [2]. Simple dielectric sheets, including those with metallic coating, are used to case handheld systems. Dielectrics with $\varepsilon_{1} \approx 1$ are preferred for radoms. However, modern packaging techniques involve more complex casing structures including measures for miniaturization. Plastic packaging will be an economical choice for LTCC structures [3] or circuits on ceramic substrates.

This paper focuses on the effects of casing on the radiation characteristics of a miniaturized patch antenna for circular polarization. Different scenarios involving metallic and dielectric casings with planar dielectric overlays are investigated.

\section{ANTENNA DESIGN}

Using a multiple resonance technique [4] for broadband performance, a circularly polarized patch antenna was designed on FR4 substrate with $\varepsilon_{\mathrm{r}}=4.2$ and substrate height $\mathrm{h}=1.58 \mathrm{~mm}$. The dimensions and the feed point of the antenna are shown in the Fig 1a. The diameter of the feeding probe is $0.5 \mathrm{~mm}$. Multiple resonances are achieved by overlapping the two square patches of different dimensions along their diagonals. The diagonal modes are excited through the appropriate location of the probe on the patch. As shown in Figs. 1a and 1b, the designed antenna has a good VSWR bandwidth as well as satisfactory axial ratio and gain performance.
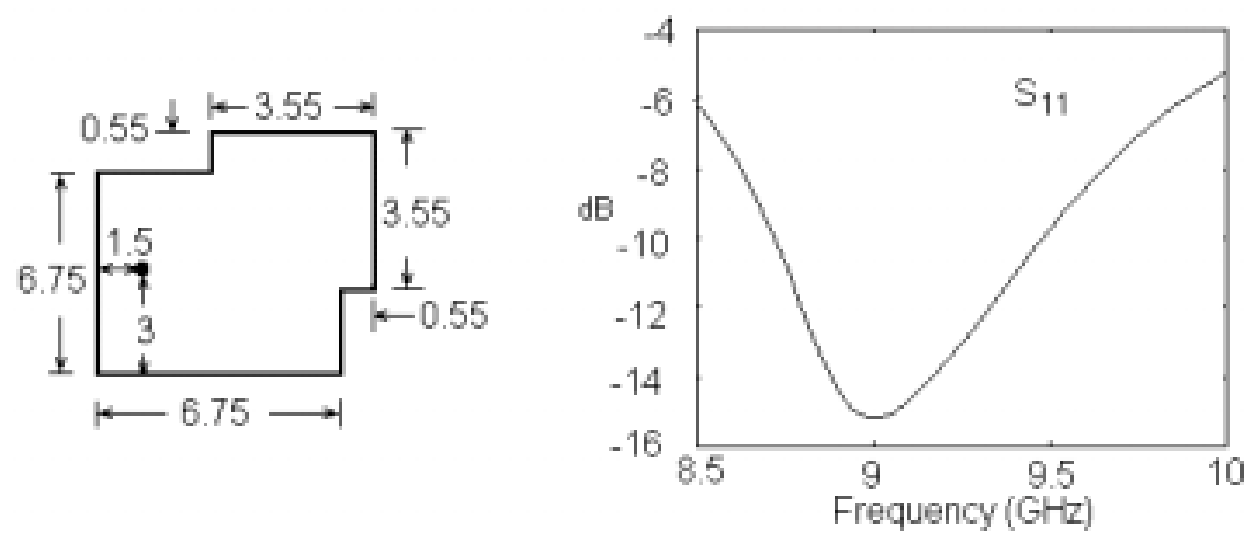

Fig.1a Patch dimensions (in $\mathrm{mm}$ ) and $\mathrm{S}_{11}$ performance without casing. 

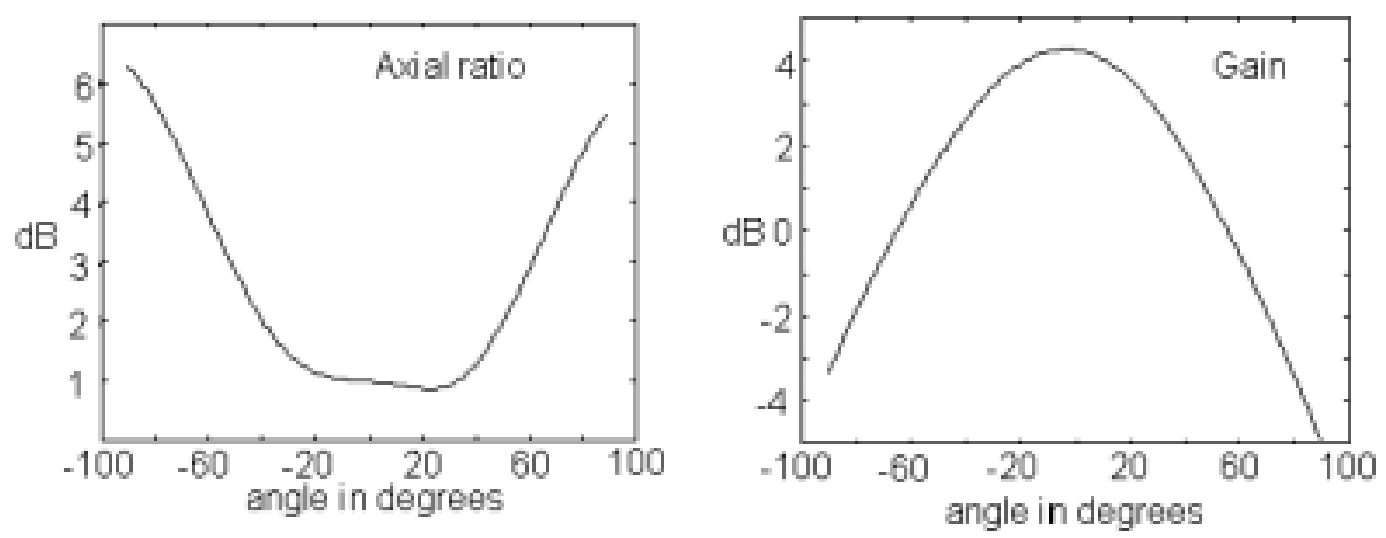

Fig.1b Axial ratio and gain performance without casing.

\section{EFFECTS OF CASING}

The input impedance of the patch antenna depends on the location of the feed point and the axial ratio depends on the current distribution (exciting modes) on the patch. Casing of the antenna disturbs the current distribution on the patch due to the reflected fields from the casing. Casing should ideally be located at a distance to the antenna to maintain its performance. This, however, makes the system too large for handheld applications. At the same time, casing should not be too close to the antenna, because the dielectric cover of the casing acts as a superstrate which shifts the operating frequency. Casing can be metallic or dielectric with dielectric top cover. Either of them will act as a cavity for the antenna. This effect is then evident in the bandwidth of the antenna, and gain and axial ratio performances will change with cavity dimensions. As an example, Fig. 2 shows the axial ratio when placed symmetrically and asymmetrically in the casing. Compared to the uncased performance in Fig. 1b, the axial ratio minimum is shifted slightly off broadside. By placing the patch asymmetrically in the casing, the axial ratio can be influenced - in this case - to produce an improved axial ratio performance.
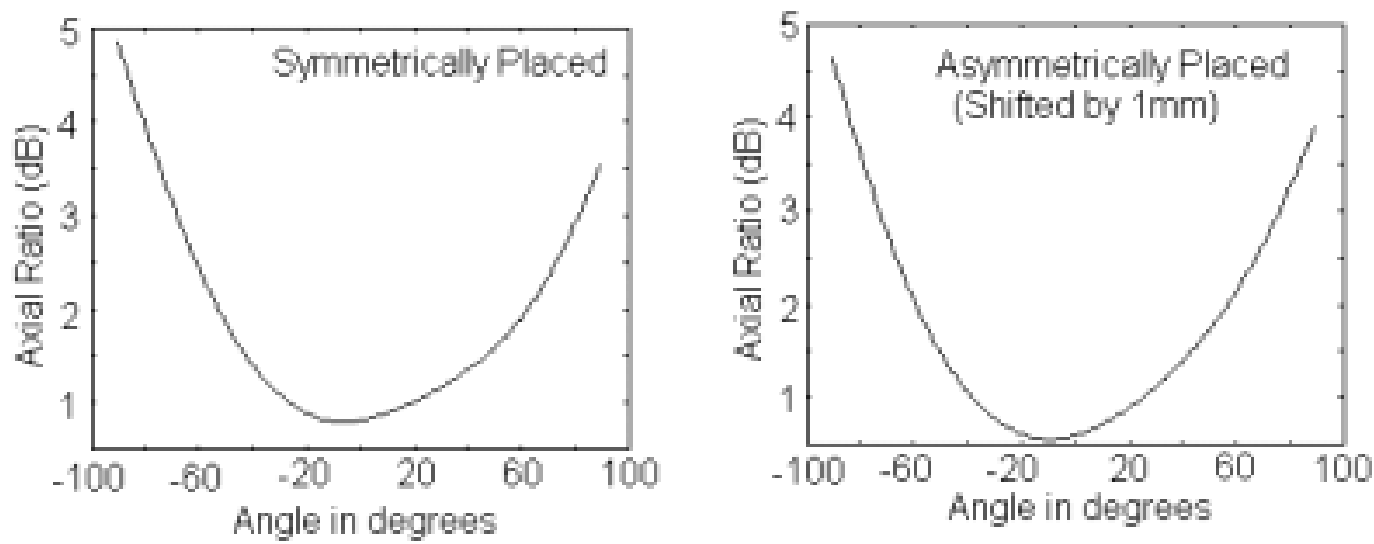

Fig.2 Axial ratio of antenna placed symmetrically and asymmetrically in casing. 
Performances of the antenna placed symmetrically and asymmetrically in a metal casing with different wall heights are shown in Fig. 3. An improvement in the gain of the antenna with metal casing is due to the focusing effect of the walls. Further increase in the wall height increases the $\mathrm{Q}$ of the cavity, thus decreasing the antenna gain. As shown already in Fig. 2, the best axial ratio shifts from broadside but can be improved due by asymmetrically placing the antenna inside the casing, the axial ratio towards broadside. Note that contrary to Fig. 2, where the axial ratio is displayed versus angle, Fig. 3 shows the performance versus frequency. Table I summarizes the results of the antenna with metal casing.
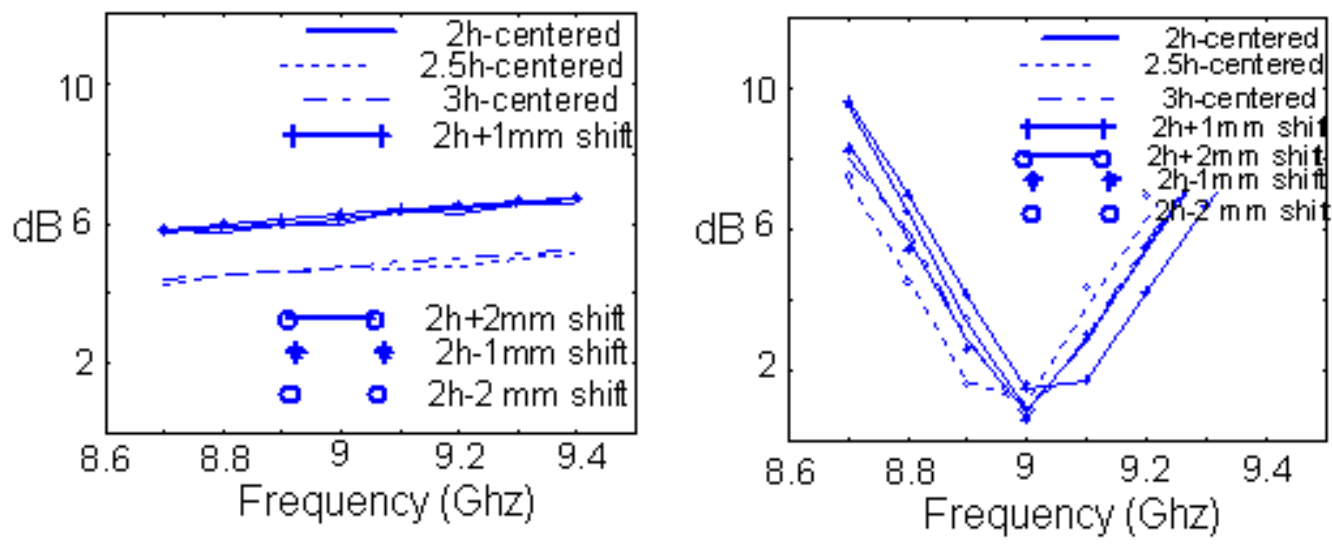

Fig. 3 Gain (left) and axial ratio (right) performance of antenna with metal casing and dielectric cover.

TABLE I - Gain and axial-ratio bandwidth performances for the metallic casing.

\begin{tabular}{|c|c|c|c|}
\hline Height of wall & $\begin{array}{c}\text { Gap } \\
\text { from feed edge }\end{array}$ & $\begin{array}{c}\text { Gain } \\
(\mathrm{dBi})\end{array}$ & $\begin{array}{c}\text { Axial Ratio } \\
(<6 \mathrm{~dB})\end{array}$ \\
\hline $1 \mathrm{~h}$ & $3 \mathrm{~h}$ & 5.5 & $5.14 \%$ \\
\hline $2 \mathrm{~h}$ & $3 \mathrm{~h}$ & 6.15 & $4.6 \%$ \\
\hline $2.5 \mathrm{~h}$ & $3 \mathrm{~h}$ & 4.6 & $4.9 \%$ \\
\hline $3 \mathrm{~h}$ & $3 \mathrm{~h}$ & 4.7 & $3.06 \%$ \\
\hline $2 \mathrm{~h}$ & $3 \mathrm{~h}+1 \mathrm{~mm}$ & 6.25 & $4.91 \%$ \\
\hline $2 \mathrm{~h}$ & $3 \mathrm{~h}+2 \mathrm{~mm}$ & 6.15 & $4.5 \%$ \\
\hline $2 \mathrm{~h}$ & $3 \mathrm{~h}-1 \mathrm{~mm}$ & 6.2 & $4.8 \%$ \\
\hline $2 \mathrm{~h}$ & $3 \mathrm{~h}-2 \mathrm{~mm}$ & 6.2 & $4.6 \%$ \\
\hline
\end{tabular}

The performance of the antenna with dielectric casing is shown in Fig. 4. The Q of the dielectric casing is small compared to the metallic casing. Therefore, the gain varies only slightly with the height of the dielectric casing. For comparison with the metal casing of Table I, the performance with dielectric casing is summarized in Table II.

\section{CONCLUSIONS}

A circularly polarized microstrip patch antenna has been designed and investigated with respect to effects introduced by casing. It is found that metallic 
casing severely influences the gain and the axial-ratio bandwidth. It also changes the direction of minimum axial ratio. By placing the patch asymmetrically in the casing, the minimum axial ratio can be improved. Dielectric casing has minimal effect on the radiation properties.
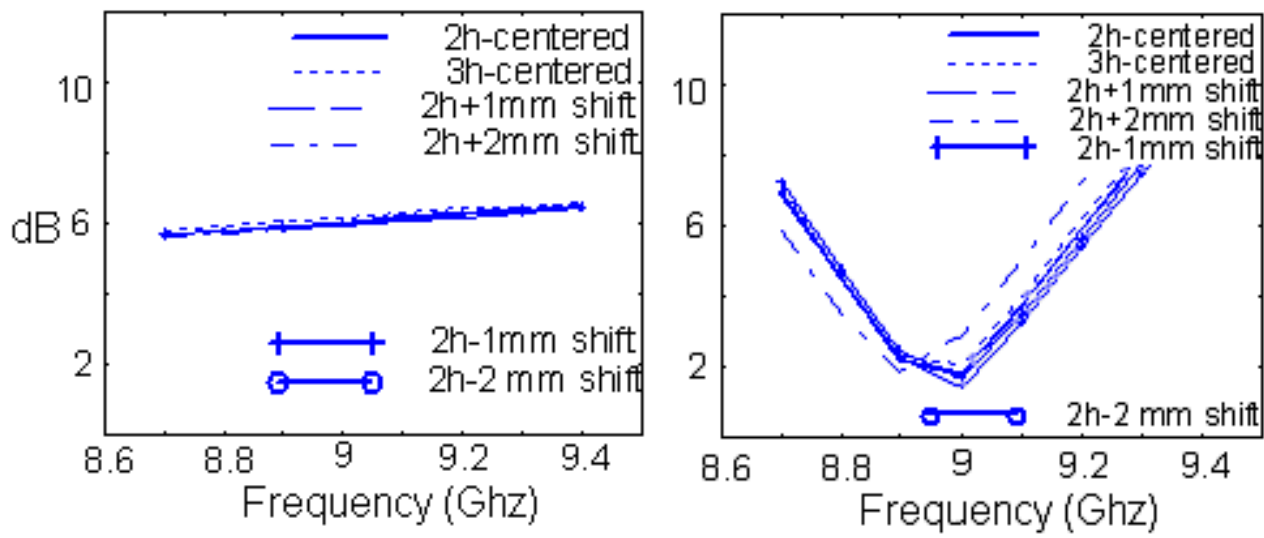

Fig. 4 Gain (left) and axial ratio (right) performance with dielectric casing and dielectric cover.

TABLE II - Gain and axial-ratio bandwidth performances for the dielectric casing.

\begin{tabular}{|c|c|c|c|}
\hline Height of wall & $\begin{array}{c}\text { Gap } \\
\text { from feed edge }\end{array}$ & $\begin{array}{c}\text { Gain } \\
(\mathrm{dBi})\end{array}$ & $\begin{array}{c}\text { Axial Ratio } \\
(<6 \mathrm{~dB})\end{array}$ \\
\hline $3 \mathrm{~h}$ & $3 \mathrm{~h}$ & 6.15 & $5.0 \%$ \\
\hline $2 \mathrm{~h}$ & $3 \mathrm{~h}$ & 6 & $5.1 \%$ \\
\hline $2 \mathrm{~h}$ & $3 \mathrm{~h}+1 \mathrm{~mm}$ & 6 & $5.2 \%$ \\
\hline $2 \mathrm{~h}$ & $3 \mathrm{~h}+2 \mathrm{~mm}$ & 6 & $5.0 \%$ \\
\hline $2 \mathrm{~h}$ & $3 \mathrm{~h}-1 \mathrm{~mm}$ & 6 & $5.3 \%$ \\
\hline $2 \mathrm{~h}$ & $3 \mathrm{~h}-2 \mathrm{~mm}$ & 5.95 & $5.5 \%$ \\
\hline
\end{tabular}

\section{REFERENCES}

[1] M.G. Pecht et.al "Electronics packaging: Material and their properties", CRC Press LLC, Washington, DC, 1999.

[2] D. Alvarez and J.P. Krusius, "Package and chip-level EMI/EMC structure design, modeling and simulation", Proc. IEEE Conf. Electronic Components and Technology, pp. 873-878, 1999.

[3] K. Lim et.al, "Development of planar antennas in multi-layer package for RF systems-on-a-package applications", IEEE AP-S Int. Symp. Dig., pp. 101104, 2001.

[4] M. Rahman and M.A. Stuchly, "Circularly polarized patch antenna with periodic structure”, IEE Proc.-Microw. Antennas Propag., Vol. 149, No. 3, pp. 141-146, June 2002. 